\title{
ПАТРОНЫ ДЛЯ ТОКАРНЫХ СТАНКОВ
}

\author{
Маркус МИХЕЛЬБЕРГЕР, Соня АУФРЕХТ
}

Ключевые слова:

механизированный

патрон, система

быстрой замены

патрона

\begin{abstract}
Предложена комбинация системы быстрой замены токарных патронов SCHUNK FSW и устройства быстрой замены кулачков, что существенно повышает гибкость производства.
\end{abstract}

\section{КОМБИНАЦИЯ КУЛАЧКОВ И СИСТЕМЫ БЫСТРОЙ ЗАМЕНЫ ПАТРОНОВ ОБЕСПЕЧИВАЕТ МАКСИМАЛЬНУЮ ГИБКОСТЬ В РАБОТЕ ТОКАРНЫХ ПАТРОНОВ}

Отсутствие возможности обработки деталей больших и малых размеров на одном станке может серьезно снизить эффективность производства. Компания из немецкого Шварценбека, LMT Fette, специализирующаяся на производстве инструментов, решила эту проблему путем переделки обычного токарного станка для сокращения времени его наладки. В предложенном решении используются кулачки и технологии быстрой замены SCHUNK, что обеспечивает возможность быстрой переналадки станка для выполнения срочных заказов от других подразделений во время обычной работы без ущерба для общей производственной эффективности (рис. 1).

Томас Франкенбергер, оператор токарного станка в компании LMT Fette Werkzeugtechnik GmbH \& Co. KG, до сих пор с содроганием вспоминает, сколько усилий требовалось, чтобы поменять рабочий патрон: «Это же целое искусство - правильно установить патрон диаметром полметра, который еще и весит 220 кило!» Даже вдвоем было нелегко попасть патроном на мелкую резьбу шпинделя. «Ошибешься на полмиллиметра - и ничего не получится, - делится опытом Томас. - Попытаешься накрутить через силу сорвешь резьбу, а это действительно большая проблема. В некоторых случаях может даже потребоваться проведение сложных работ по восстановлению резьбы на шпинделе. В прошлом, чтобы поменять патрон, нужен был опыт и чутье, приходилось потратить много времени и сил. Теперь у нас быстросменные патроны SCHUNK, так что поменять патрон я могу и сам, причем и сил у меня уходит меньше, и риск что-нибудь поломать куда ниже. Раньше на замену патрона уходило от 45 мин до часа, причем иногда мне нужна была помощь двух коллег, а теперь я меняю патрон полностью сам, всего за 15 мин, и это с учетом всяких сопутствующих работ, вроде очистки, смазки и отправки снятого патрона на хранение».

\section{УСТАНАВЛИВАЕМЫЙ ПАТРОН АВТОМАТИЧЕСКИ ЦЕНТРИРУЕТСЯ НА ГИБКОМ ПОСАДОЧНОМ КОНУСЕ ЗАПАТЕНТОВАННОЙ КОНСТРУКЦИИ}

На смену множеству крепежных болтов пришла система быстрой замены SCHUNK ROTA FSW, в которой надежная фиксация патрона осуществляется всего одним болтом (рис. 2). Благодаря наличию посадочного конуса запатентованной конструкции универсальный адаптер автоматически насаживает патрон на шпиндель токарного станка и центрирует его с высокой точностью. Запатентованная схема двойного хода гарантирует передачу огромного тянущего и толкающего усилия, оптимальную плоскость рабочей поверхности и великолепную жесткость фиксации (рис. 3). Патрон самофиксируется с геометрическим замыканием. Во избежание сбоев во время работы статус фиксации патрона постоянно отображается на дисплее. «С устройством

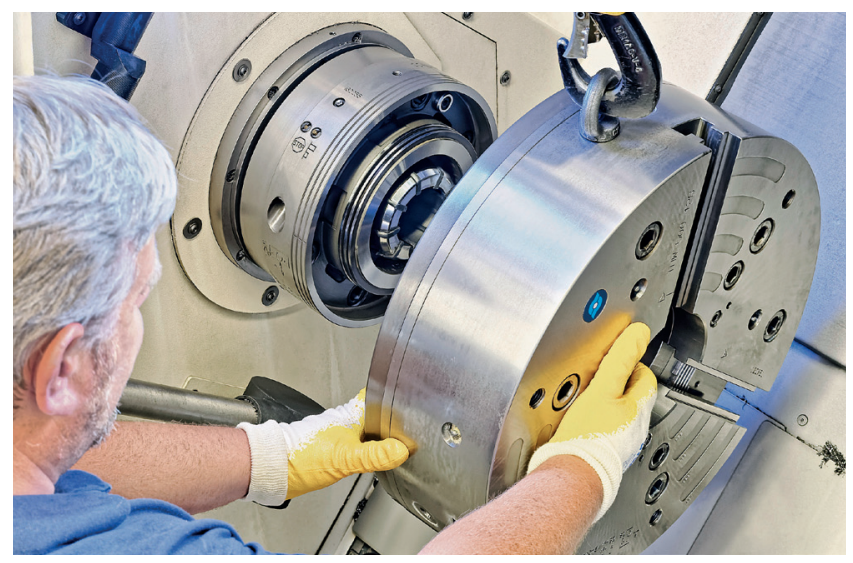

Puc. 1. Благодаря системе быстрой замены SCHUNK FSW смена патрона на токарном станке на заводе LMT Fette занимает всего 15 мин с учетом необходимой очистки, смазки и отправки патрона на хранение. Механизированный патрон ROTA THW, который на ваших глазах с легкостью меняет Томас Франкенбергер, весит более 200 кг

Здесь и далее ипользованы фото SCHUNK 
быстрой смены патрон заменять стало намного легче, говорит Томас Франкенбергер. - Я устанавливаю патрон и закручиваю один болт ключом с динамометром. Патрон центрируется автоматически и надежно фиксируется в нужном положении. Почти без усилия, - продолжает Томас. - Кроме того, гарантирована высокая стабильность позиционирования» (рис. 4). «Вначале мы тщательно все контролировали, пока не убедились, что все работает идеально, - рассказывает Тиес Манн, инженер, отвечающий за программирование станков с ЧПУ в LMT Fette и реализацию проекта внедрения системы быстрой замены патрона. - Теперь мы больше дажене проверяем точность установки патрона, поскольку уверены, что система работает. Кроме того, по сравнению с обычной сменой патрона меньше времени тратится на чистку, - продолжает он. - Систему удобно использовать, легко чистить и обслуживать», - уверяет Манн. Максимальная эксплуатационная надежность, особенно при обработке крупных заготовок и больших рабочих ходах, обеспечивается путем проведения регулярных инспекций и технического обслуживания патронов и устройств быстрой смены патрона техническими специалистами SCHUNK.

Система быстрой смены особенно хорошо зарекомендовала себя при работе с патронами большого размера весом свыше 200 кг. Нередко во время сложной процедуры установки тяжелый патрон раскачивается и бьет по концу шпинделя, повреждая его. Конструкция новой системы SCHUNK практически исключает такой риск. Вдобавок, система ROTA FSW уменьшает объем работ по очистке и уменьшает риск попадания внутрь патрона грязи и стружки. Предусмотрено три размерных варианта системы быстрой замены патрона: для патронов диаметром менее 260 мм, от 315 до 400 мм и от 400 до 630 мм. Устройство можно установить практически на любой токарный станок. При этом возможно использование как ручных, так и механизированных патронов. Использование системы никак не сказывается на зажимном усилии патрона и допустимой рабочей скорости. Само устройство имеет небольшую высоту, поэтому практически не требует дополнительного пространства для установки. SCHUNK ROTA FSW подходит и для установки на современных многоцелевых токарных станках, поскольку отличается большим диаметром отверстия под патрон. Уже имеющиеся зажимные устройства можно легко доработать для многократного использования с системой быстрой замены.

\section{ФИКСАЦИЯ ОБРАБАТЫВАЕМЫХ ДЕТАЛЕЙ ДЛИНОЙ БОЛЕЕ 500 ММ И ВЕСОМ СВЫШЕ 500 КГ}

На производстве LMT Fette постоянно возникала одна и та же проблема. Поначалу инженеры пытались обойтись патроном ROTA THW 500 на новом универсальном токарном станке, но вскоре стало понятно, что использование компонентов малого размера сопряжено с огра-

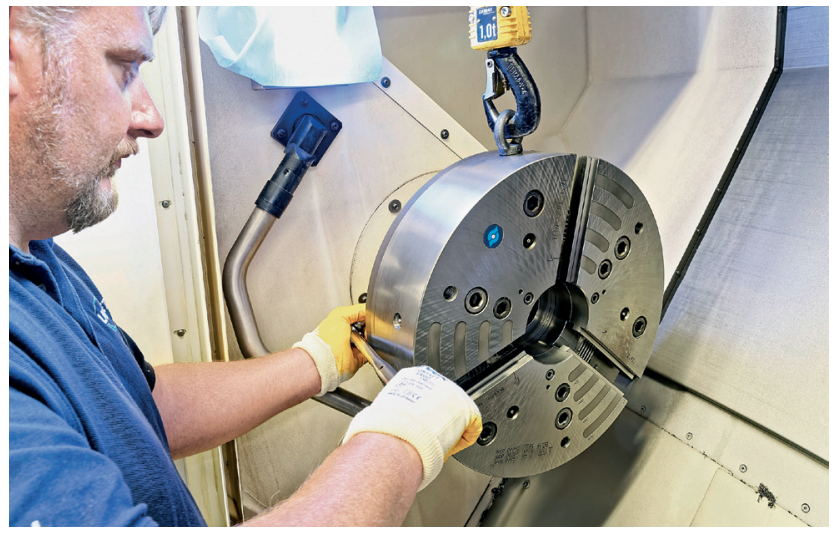

Puc. 2. Фиксация патрона в системе быстрой замены SCHUNK ROTA FSW обеспечивается всего одним болтом. С его помощью система автоматически центрирует корпус патрона

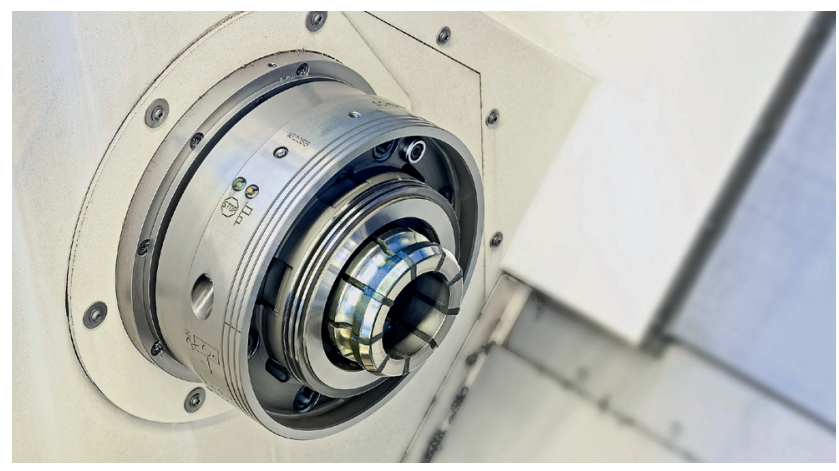

Puc. 3. Применение универсального посадочного конуса запатентованной конструкции обеспечивает высочайшую точность центрирования патрона. Запатентованная схема двойного хода ROTA FSW, реализованная в системе быстрой замены патрона, гарантирует передачу огромного тянущего и толкающего усилия, оптимальную плоскость рабочей поверхности и великолепную жесткость фиксации



Puc. 4. Для замены оператору нужно просто насадить патрон на шпиндель. Остальное система быстрой замены сделает сама 


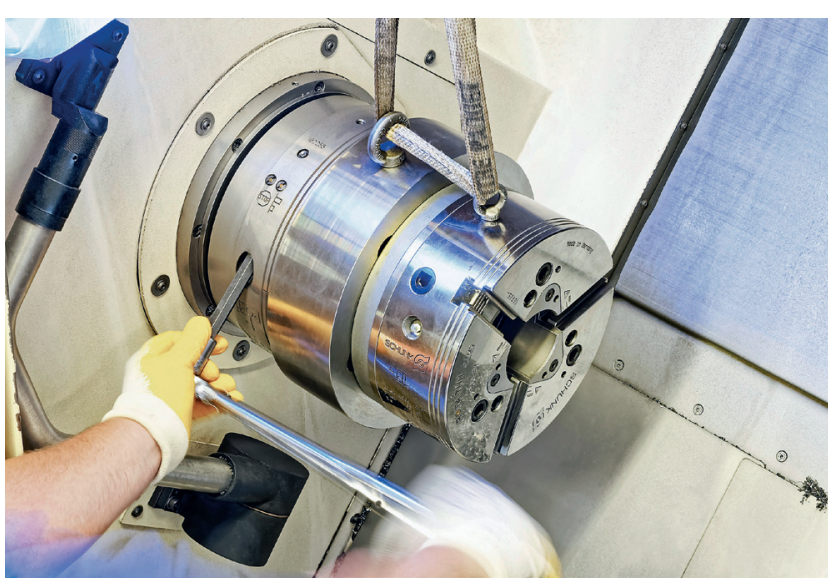

PUC. 5. Патрон меньшего размера SCHUNK ROTA THW plus 260 устанавливается на устройстве быстрой замены патрона ROTA FSW через адаптер

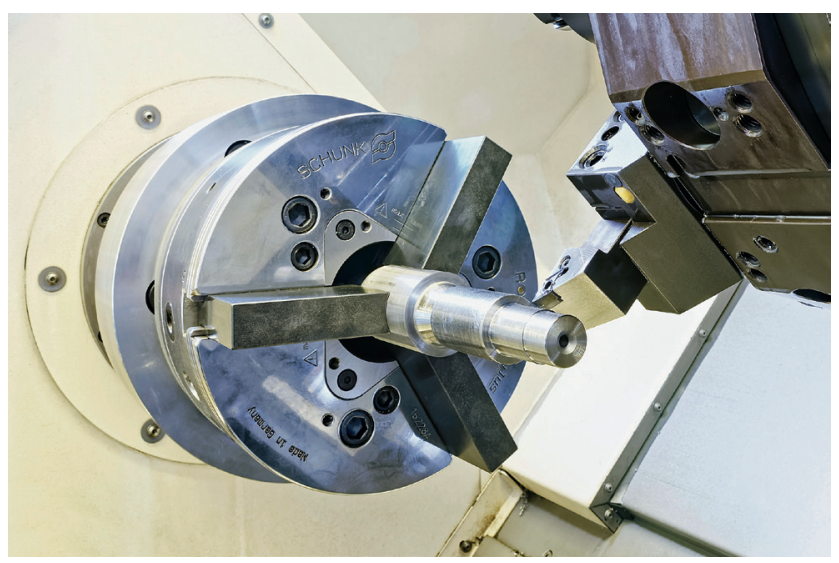

Puc. 6. Используя патрон SCHUNK ROTA THW plus 260, оператор станка на заводе LMT Fette может работать даже с деталями небольшого размера

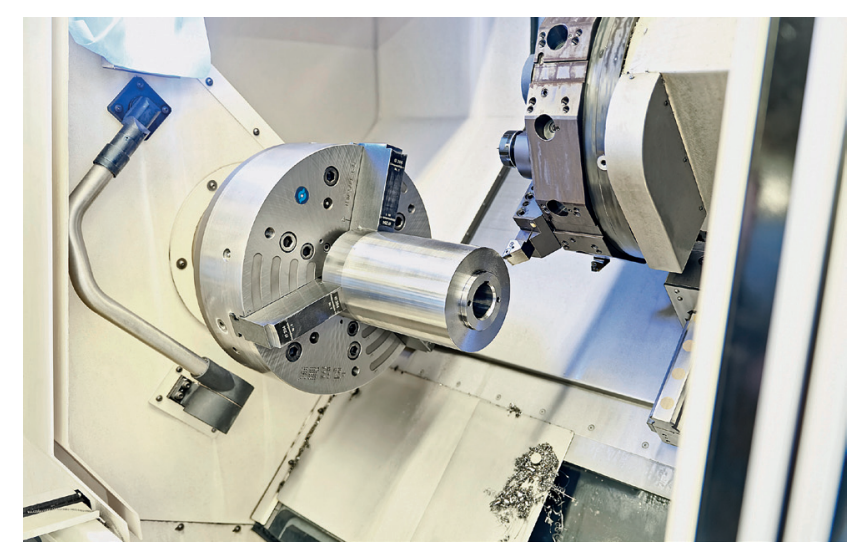

PUC. 7. C помощью SCHUNK ROTA THW оператор станка на заводе LMT Fette легко закрепляет заготовки для обработки длиной более 500 мм и весом свыше 500 кг ничением по скорости вращения. Поэтому было решено использовать механизированный патрон ROTA THW 500 в сочетании с системой быстрой замены ROTA FSW спатроном меньшего размера ROTA THW plus 260. Патрон диаметром 260 мм устанавливается на системе быстрой замены с помощью специального монтажного фланца (рис. 5). Таким образом, появляется возможность обрабатывать заготовки диаметром от 60 до 550 мм (рис. 6). Большую роль при этом играет система быстрой замены патрона. Например, на ней легко устанавливается механизированный патрон под сегментные фрезы LMT длиной до 520 мм и весом более 500 кг для торцового фрезерования и выборки центрального отверстия (рис. 7). Единственное, для большей стабильности при обработке внешнего контура, на задней бабке устанавливается дополнительный упор. Такая схема позволяет с легкостью сверлить центральные отверстия.

Высокая точность зажима в устройстве быстрой замены кулачков позволяет LMT Fette в полной мере использовать возможности работы с заготовками самого разного размера без лишней смены рабочего патрона. Как правило, с системой используются механизированные патроны, рассчитанные на мелкосерийное и среднесерийное производство. Главное преимущество состоит в том, что после работы комплект кулачков патрона можно использовать снова и снова, поскольку система отличается высокой стабильностью позиционирования ( $<0,02$ мм для патрона ROTA THW plus 260 и $<0,03$ мм для патрона ROTA THW 500) (рис. 8). Кроме того, замена кулачков патрона совсем не требует времени, а это - весомое преимущество для оператора, потому что каждый кулачок может весить до 8 кг (рис. 9). «Я просто вставляю кулачок в гнездо и фиксирую, воодушевленно делится Томас Франкенбергер. - Ничего не надо измерять и проверять, я совершенно уверен, что кулачок встал в нужное положение». Чтобы исключить риск ошибки оператора, в механизме фиксации предусмотрен специальный шариковый замок, который не позволяет извлечь фиксирующий шплинт, если клиновой фиксатор не защелкнулся на хвостовике кулачка. Специальная система смазки обеспечивает непрерывную подачу смазки во все наиболее значимые точки. «В среднем радиальное биение вращающихся частей не превышает 0,03 мм. И такая точность достигается совершенно без усилий, - говорит Тиес Манн. - Вдобавок, станок теперь имеет максимальный рабочий ход, потому что зажим занимает не более 10 мм». На предприятии LMT Fette используются специальные зажимные кулачки SCHUNK, рассчитанные на фиксацию дисков большого размера диаметром до 600 мм на патронах серии 500.

\section{ОТЛИЧНАЯ ГИБКОСТЬ ДЛЯ СРОЧНЫХ ЗАКАЗОВ}

После перехода на систему быстрой замены патрона с быстросменными кулачками компания 




Puc. 8. Благодаря конструкции SCHUNK ROTA THW 500 смена кулачков патрона, которые могут весить до 8 кг, выполняется очень быстро. Применение системы быстрой замены патрона с быстросменными кулачками обеспечивает радиальное биение <0,03 мм без дополнительных настроек

LMT Fette серьезно повысила гибкость при производстве зубчатых колес. «Кулачки менять приходится раза четыре или пять в день, а сам патрон - раза три-четыре в неделю», - объясняет Томас Франкенбергер. Например, обычно в одной партии 16 заготовок, обрабатываемых сегментной фрезой. Как правило, заготовки большого размера изготавливают в виде цельной конструкции. Благодаря высокой производственной гибкости стало возможно производить краны для передачи другому подразделению партиями от 6 до 12 шт. Появилась возможность нарезать резьбу размером до М52 при длине заготовки до 500 мм. Кроме того, станок можно быстро задействовать для выполнения срочных поручений от других отделов. По словам Тиеса Манна, вложения полностью окупились повышением



Puc. 9. Заранее подготовленные кулачки для механизированного патрона SCHUNK ROTA THW plus 260 меняются с высокой точностью всего за несколько простых действий

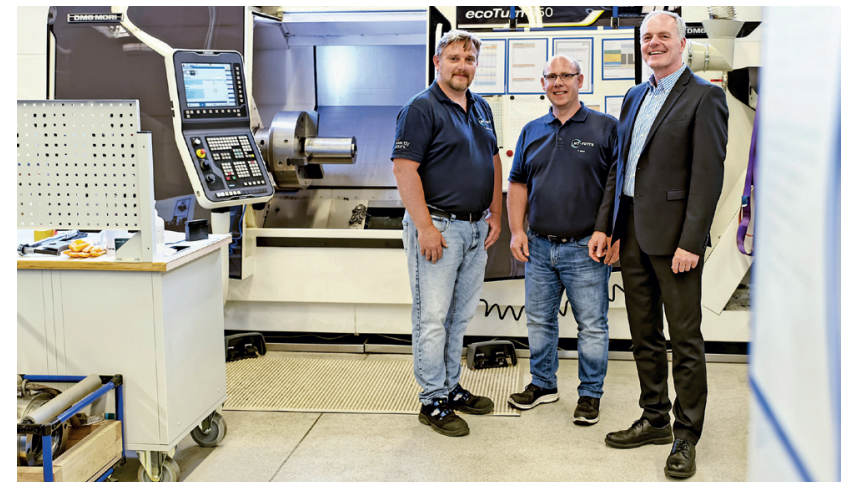

Puc. 10. Консультант компании SCHUNK Йенс Мартин (справа) оказывал поддержку Тиесу Манну (в центре) и Томасу Франкенбергеру (слева) во время реализации проекта, который помог повысить производственную гибкость токарных станков

\section{LMT FETTE}

Компания LMT Fette - один из ведущих производителей червячных фрез и резьбонакатных головок для комплектации промышленных предприятий. Компания была основана в 1908 году. Совместно с LMT Kieninger, компания LMT Fette образует экспертно-консультационный центр группы компаний LMT Group - семейного холдинга. На 20-ти заводах группы LMT Group по всему миру трудятся более 2200 человек, что делает ее одним из ведущих специализированных предприятий в сфере машиностроения и производства инструментов.

производственной гибкости компании. Он утверждает, что производство на заводе в Шварценбеке настолько точно скоординировано, что простой даже одного станка в течение нескольких часов может нарушить планы. «Поэтому гибкость для нас самое главное, - говорит программист станков. - Ведь только так можно быстро среагировать и устранить возникающую проблему. Мы предлагаем систему быстрой переналадки станка, которая идеально подходит, когда нужно быстро повысить скорость и эффективность производства» (рис. 10).

\section{МИХЕЛЬБЕРГЕР Маркус - \\ глава отдела продаж систем зажима}

\section{АУФРЕХТ Соня -}

дипломированный специалист по экономике предприятий (BA), журналист (FJS), менеджер по корпоративным коммуникациям и связям с общественностью 